\title{
Update Breast Cancer 2019 Part 5 - Diagnostic and Therapeutic Challenges of New, Personalised Therapies in Patients with Advanced Breast Cancer
}

\section{Update Mammakarzinom 2019 Teil 5 - diagnostische und therapeutische Herausforderungen neuer personalisierter Therapien bei Patientinnen mit fortgeschrittenem Mammakarzinom}

\section{(ㄷ) (1) (오 $€$}

Authors

Manfred Welslau ${ }^{1}$, Andreas D. Hartkopf ${ }^{2}$, Volkmar Müller ${ }^{3}$, Achim Wöckel ${ }^{4}$, Michael P. Lux ${ }^{5}$, Wolfgang Janni ${ }^{6}$, Johannes Ettl ${ }^{7}$, Diana Lüftner ${ }^{8}$, Erik Belleville ${ }^{9}$, Florian Schütz ${ }^{10}$, Peter A. Fasching ${ }^{11}$, Hans-Christian Kolberg ${ }^{12}$, Naiba Nabieva ${ }^{11}$, Friedrich Overkamp ${ }^{13}$, Florin-Andrei Taran ${ }^{2}$, Sara Y. Brucker ${ }^{2}$, Markus Wallwiener ${ }^{10}$, Hans Tesch $^{14}$, Andreas Schneeweiss ${ }^{15}$, Tanja N. Fehm ${ }^{16}$

\section{Affiliations}

1 Onkologie Aschaffenburg, Aschaffenburg, Germany

2 Department of Obstetrics and Gynecology, University of Tübingen, Tübingen, Germany

3 Department of Gynecology, Hamburg-Eppendorf University Medical Center, Hamburg, Germany

4 Department of Gynecology and Obstetrics, University Hospital Würzburg, Würzburg, Germany

5 Kooperatives Brustzentrum Paderborn, Klinik für Gynäkologie und Geburtshilfe Frauenklinik St. Louise, Paderborn, St. Josefs-Krankenhaus, Salzkotten, Germany

6 Department of Gynecology and Obstetrics, Ulm University Hospital, Ulm, Germany

7 Department of Obstetrics and Gynecology, Klinikum rechts der Isar, Technical University of Munich, Munich, Germany

8 Charité University Hospital, Campus Benjamin Franklin, Department of Hematology, Oncology and Tumour Immunology, Berlin, Germany

9 ClinSol GmbH \& Co KG, Würzburg, Germany

10 Department of Obstetrics and Gynecology, University of Heidelberg, Heidelberg, Germany

11 Erlangen University Hospital, Department of Gynecology and Obstetrics, Comprehensive Cancer Center ErlangenEMN, Friedrich-Alexander University Erlangen-Nuremberg, Erlangen, Germany

12 Department of Gynecology and Obstetrics, Marienhospital Bottrop, Bottrop, Germany

13 OncoConsult Hamburg GmbH, Hamburg, Germany

14 Oncology Practice at Bethanien Hospital Frankfurt, Frankfurt, Germany
15 National Center for Tumor Diseases, Division Gynecologic Oncology, University Hospital Heidelberg, Heidelberg, Germany

16 Department of Gynecology and Obstetrics, University Hospital Düsseldorf, Düsseldorf, Germany

Key words

advanced breast cancer, metastases, therapies, mutation testing, immunotherapy

Schlüsselwörter

fortgeschrittenes Mammakarzinom, Metastasen, Therapien, Mutationstestungen, Immuntherapie

$\begin{array}{ll}\text { received } & 24.7 .2019 \\ \text { revised } & 4.8 .2019 \\ \text { accepted } & 22.8 .2019\end{array}$

Bibliography

DOI https://doi.org/10.1055/a-1001-9952

Geburtsh Frauenheilk 2019; 79: 1090-1099 @ Georg Thieme

Verlag KG Stuttgart · New York | ISSN 0016-5751

\section{Correspondence}

Peter A. Fasching, MD

Erlangen University Hospital, Department of Gynecology and Obstetrics, Comprehensive Cancer Center Erlangen EMN, Friedrich Alexander University of Erlangen-Nuremberg Universitätsstraße 21-23, 91054 Erlangen, Germany peter.fasching@uk-erlangen.de

$\Theta$ Deutsche Version unter: https://doi.org/10.1055/a-1001-9952 


\section{ABSTRACT}

Significant advancements have been made in recent years in advanced breast cancer and nearly all of them have been in the field of targeted therapy. Pertuzumab and trastuzumabemtansine (T-DM1) have been able to be introduced in HER2-positive breast cancer. Now other anti-HER2 therapies are being developed (e.g. margetuximab, DS-8201a, pyrotinib) which can overcome other resistance mechanisms in the HER2 signalling pathway. In the field of hormone-receptorpositive breast cancer, an mTOR inhibitor and CDK4/6 inhibitors were introduced in the past. Now the introduction of the first PI3K inhibitor is forthcoming and this inhibitor will involve genetic testing of the tumour for a mutation in the PIK3CA gene. There are also significant advancements in triple-negative breast cancer: By combining chemotherapy and immunotherapy, an advantage for overall survival was able to be demonstrated in a subgroup (immune cells PD-L1-positive). The PARP inhibitor therapy for HER2-negative patients with a germ line mutation in BRCA1 or BRCA2 was also associated with an improved overall survival in a subgroup. These promising new study results are summarised in this review.

\section{ZUSAMMENFASSUNG}

Beim fortgeschrittenen Mammakarzinom sind in den letzten Jahren deutliche Fortschritte erzielt worden, diese fast alle auf dem Gebiet der zielgerichteten Therapie. Pertuzumab und Trastuzumab-Emtansin (T-DM1) konnten beim HER2-positiven Mammakarzinom eingeführt werden. Nun sind weitere Anti-HER2-Therapien in der Entwicklung (z. B. Margetuximab, DS-8201a, Pyrotinib), die weitere Resistenzmechanismen im HER2-Signalweg überwinden können. Auf dem Gebiet des hormonrezeptorpositiven Mammakarzinoms wurden in der Vergangenheit ein mTOR-Inhibitor und CDK4/6-Inhibitoren eingeführt. Nun steht die Einführung des ersten PI3K-Inhibitors bevor, die eine genetische Testung des Tumors auf eine Mutation im Gen PIK3CA mit sich bringen wird. Beim tripelnegativen Mammakarzinom gibt es ebenfalls deutliche Fortschritte: Durch Kombination von Chemo- plus Immuntherapie konnte ein Vorteil für das Gesamtüberleben in einer Subgruppe (Immunzellen PD-L1-positiv) gezeigt werden. Die PARP-Inhibitor-Therapie für HER2-negative Patientinnen mit einer Keimbahnmutation in BRCA1 oder BRCA2 war ebenfalls in einer Subgruppe mit einem verbesserten Gesamtüberleben assoziiert. Diese vielversprechenden, neuen Studienergebnisse werden in dieser Übersichtsarbeit zusammengefasst.

\section{Introduction}

The new developments in the therapy of advanced breast cancer are taking place at a rate which has never been seen before. While only few new drugs were approved by 2012, the approval of 10 new drugs has been able to be observed since then. These rapid developments call for a high degree of attention from all sides (patients, physicians, health insurance companies, health committees) to ensure therapeutic efficacy and patient safety. In this review article, we focus on the latest study results which were recently published or presented at national or international professional conferences.

\section{Metastatic HER2-negative, Hormone- Receptor-Positive Breast Cancer}

Many study designs currently concentrate on analysing the efficacy of inhibitors of the PI3K/AKT/PTEN signalling pathway [ 1 in patients with advanced breast cancer. Jones et al. investigated the significance of the AKT inhibitor capivasertib in combination with fulvestrant within the framework of the FAKTION study (phase II). A significant PFS advantage was seen (4.8 vs. 10.3 months) versus those patients who were treated only with fulvestrant, independent of an activation of the PI3K/AKT/PTEN signalling pathway. Likewise, improved overall survival - however not statistically significant - was seen on the endocrine combination therapy [2]. These results are promising and must be accordingly confirmed in a phase III study.

\section{New data from the MONALEESA-7 and MONALEESA-3 study}

In the premenopausal, metastatic situation as well, the use of CDK4/6 inhibitors in combination with a GnRH analogue is by now the therapeutic standard. The initial data on overall survival following 35 months of follow-up observation in the Monaleesa7 study were recently published in full [3]. In this study, 672 premenopausal patients with hormone-receptor-positive, HER2-negative, metastatic breast cancer were treated with an endocrine combination therapy (non-steroidal aromatase inhibitor or tamoxifen plus ovarian function suppression) with or without the addition of ribociclib. The most current evaluation demonstrated a significant advantage in overall survival $(\mathrm{HR}=0.712 ; 95 \% \mathrm{Cl}$ : 0.54-0.95; $p=0.00973$ ) with an estimated survival rate after 42 months of 70.2 vs. $46.0 \%$. The treatment following the study therapy did not differ between the arms. Thus the Monaleesa-7 study is the first study with a CDK4/6 inhibitor which demonstrates a survival advantage in the overall study population.

Not reported or published during a conference but rather issued in a press release [4], the Monaleesa-3 study [5] is the second study which is also said to have shown an advantage for overall survival. How great the effect is cannot yet be said due to the lack of any publication at this present time.

\section{New therapies as alternative to chemotherapies}

Another study on premenopausal patients was able to prove the significance of endocrine therapy in combination with CDK 4/6 inhibitors in the metastatic situation [6]. The Korean study KCSG-BR 15-10 compared chemotherapy with capecitabine with an endo- 
crine therapy in 184 patients with metastatic disease. The patients in the endocrine therapy arm received exemestane plus a $\mathrm{GnRH}$ analogue in combination with palbociclib. All patients had previous therapy with tamoxifen, about $50 \%$ did not receive any previous therapy in the metastatic situation, about $20 \%$ had already received chemotherapy for the metastatic disease. The assessment revealed a significantly longer PFS for the endocrine combination than with capecitabine (20.1 vs. 14.4 months, $\mathrm{HR}=0.659 ; 95 \% \mathrm{Cl}: 0.44-0.99)$. The advantage with regard to the PFS could be observed independently from previous chemotherapy. Other parameters such as the therapeutic response were comparable. For premenopausal patients, endocrine therapy in combination with a CDK4/6 inhibitor is just as effective as chemotherapy. These data support the recommendation of the AGO "Mamma" organ committee on the preferred use of endocrine therapy in the metastatic situation, even if the reality of therapy in Germany (and also other countries) does not yet entirely reflect this recommendation [7].

\section{Compliance as the focus of antihormone therapies}

In a study from Germany, adherence data during aromatase monotherapy in patients with advanced breast cancer were recently published [8]. This study showed that after 12 months, approx. $40 \%$ of patients had discontinued therapy without progression if an adverse effect occurred in the first 30 days of therapy. This issue could be of particular significance for patients on therapy with CDK4/6 inhibitors and antihormone therapy because on this therapy, adverse effects occur more frequently than on antihormone monotherapy. A summary of the data in this regard is shown in $>$ Table 1.

\section{Immunotherapies in hormone-receptor-positive breast cancer}

Checkpoint inhibitors currently play a large role in triple-negative breast cancer. Tolaney et al. recently presented data from a randomised phase II study for the first time which investigated the significance of pembrolizumab $(P)$ in combination with eribulin (E) in 88 patients who underwent extensive endocrine pretreatment with an indication for chemotherapy (at least 2 endocrine therapies, 0-2 chemotherapies) [9]. A crossover to the pembrolizumab arm was allowed in the event of progression. No difference was seen in the primary endpoint PFS (E + P: 4.1 months vs. E: 4.2 months; $P=0.33$ ). The response rates and the overall survival were independent of the PD-L1 status. However, the extent to which factors such as pretreatment of the patients, chemotherapy with eribulin, or the inclusion of PD-L1-negative patients could be a reason for the lack of benefit of the addition of pembolizumab cannot be conclusively explained within the scope of this study.

\section{Routine clinical practice is preparing for PIK3CA mutation testing}

The data from the SOLAR-1 study were already released at the ESMO Congress 2018. These data are now available as a full publication [10]. The PI3K inhibitor alpelisib has already been approved in the US. In the randomised SOLAR-1 study, patients who had already received antihormone therapy were randomised

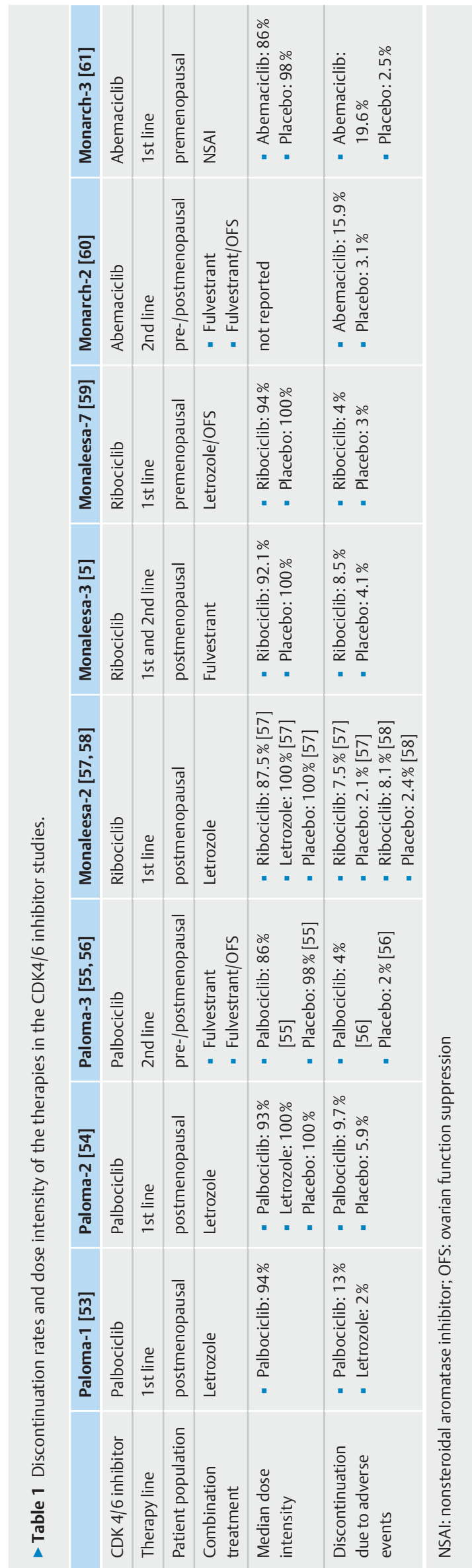


for therapy with fulvestrant vs. fulvestrant + alpelisib (PI3K inhibitor). Patients with a tumour mutation in the PIK3CA gene had a prolonged median PFS on therapy with fulvestrant + alpelisib (11.0 vs. 5.7 months; $\mathrm{HR}=0.65 ; 95 \% \mathrm{Cl}: 0.50-0.85 ; \mathrm{p}<0.001$ ). In the group of patients without a tumour mutation in the PIK3CA, no significant difference between the randomisation arms could be found. Thus in the future, tumours must also be tested for such a mutation. The existing infrastructure within the framework of mutation testing on tumours can be used here for the testing. These tests will be able to be performed by the pathologist. One particular feature is that the SOLAR-1 study showed that, through mutation testing in the blood, a population of patients who benefit from therapy with alpelisib could also be identified [10]. The testing of mutations in so-called circulating tumour DNA is a breakthrough in the treatment of patients with breast cancer. In addition, other test methods are also available: While tumour testing for mutations in panel genes is already established in many cancer centres with next-generation sequencing methods, in the US, the indication was also combined with a PCR (polymerase chain reaction)-based assay as a so-called companion diagnostic. This test enables testing for mutations in PIK3CA with the more advantageous PCR method. Which methods are more sensitive or can be better implemented in clinical practice is currently the subject of scientific investigations.

\section{Metastatic HER2-positive Breast Cancer}

\section{Pertuzumab in the long-term follow-up observation}

The survival of metastatic, HER2-positive patients has significantly improved in recent years through the use of monoclonal antibodies against HER2, the double blockade with trastuzumab and pertuzumab, and therapy with the antibody toxin conjugate (ADC) T-DM1. Compared to therapy based on docetaxel and trastuzumab, the double blockade with pertuzumab and trastuzumab in combination with docetaxel in the CLEOPATRA study led to a substantial prolongation of the overall survival of 15.7 months [11, 12]. This analysis was performed with a median follow-up of 50 months. Recently, the final analysis of this study was presented with a median follow-up of 99 months [13]. Even after more than 8 years of follow-up observation, the survival advantage continues. In absolute terms, $37 \%$ of the patients in the group of patients treated with the double blockade were alive after 8 years, while only $23 \%$ in the group who had received only chemotherapy and trastuzumab were alive. The hazard ratio for the overall survival was still 0.69 (95\% Cl: $0.58-0.82)$. Thus the data to date were also able to be confirmed with a longer follow-up observation period. Here it is also worth noting that even after 8 years of a metastatic disease, $37 \%$ of the patients were still alive [13]. This also corresponds to our experience in the treatment of this population and strikingly represents the significance of the double blockade.

\section{Neratinib in the metastatic situation}

Currently the combination of pertuzumab, trastuzumab and a taxane is standard in first-line therapy. This therapy is generally then followed by therapy with T-DM1 in the second line [14]. There is consensus that a HER2 blockade is still also useful in the third and further lines. The randomised phase III study NALA investigated the comparison of neratinib + capecitabine versus lapatinib + capecitabine in the patient population with HER2-positive, metastatic breast cancer who already had two or more anti-HER2-targeted therapies. 621 patients were randomised, 307 in the neratinib + capecitabine arm, 314 in the lapatinib + capecitabine arm. An improvement in the PFS for the combination with neratinib was able to be shown. The hazard ratio was 0.76 (95\% Cl: $0.63-$ $0.93 ; p=0.006)$. The survival rates after 6 and 12 months were 90.2 vs. $87.5 \%$ and 72.5 vs. $66.7 \%$ with a trend for the combination of neratinib and capecitabine, however not significant $(\mathrm{HR}=0.88 ; 95 \% \mathrm{Cl}: 0.72-1.07)$. The overall response rate was higher in the neratinib group (32.8 vs. $26.7 \%$ ), as was the clinical benefit rate ( 44.5 vs. $35.6 \%$ ). The longer response period to therapy with neratinib and capecitabine with an HR of 0.50 was also noteworthy ( $95 \% \mathrm{Cl}: 0.33-0.74)$. Also striking was the longer time until the appearance of symptomatic brain metastases on neratinib. The treatment-related adverse effect rates were approximately comparable in both groups, whereby grade III diarrhoea was noted in the neratinib arm in $24.4 \%$ of patients vs. $12.5 \%$ in the comparison arm [15].

\section{New anti-HER2 therapies}

In view of the great success of the anti-HER2 therapies even when used after multiple lines of therapy, the search for effective antiHER2 therapies naturally continues so that HER2-positive patients can also continue to be treated after progression with an effective anti-HER2 therapy. An example which was already presented in the past is the ADC DS-8201a which binds trastuzumab with a topoisomerase inhibitor and demonstrated good efficacy in early therapeutic studies [16-18]. Recently, two additional anti-HER2 therapies were recently presented: pyrotinib [19] and margetuximab [20].

Pyrotinib is a tyrosine receptor kinase inhibitor which binds HER1, HER2, and HER4. In early studies, it was shown that it has promising efficacy in HER2-positive patients and that it is well tolerated. Now the data from the phase III study were presented [19]. The precondition was HER2-positive, metastatic breast cancer and progression during or after therapy with trastuzumab. More than 2 previous chemotherapies were not permitted. In the 2:1 randomised study, 279 patients received either a combination of capecitabine + pyrotinib or capecitabine + placebo. The median PFS was significantly better in the pyrotinib group with 11.1 vs. 4.1 months in the control group (HR 0.18; $95 \% \mathrm{Cl}: 0.13-$ 0.26 ; $p<0.001)$. The overall response, at $68.6 \%$, was also considerably better than in the placebo group (16\%). The study allowed a crossover and 71 patients received pyrotinib as monotherapy after progression and achieved a response rate of $38 \%$ and a median PFS of 5.5 months. The most common grade 3 adverse effects were diarrhoea (30.8 vs. $12.8 \%$ ) and hand-foot syndrome (15.7 vs. $5.3 \%)$ [19].

Margetuximab is an anti-HER2 antibody which is directed against the same epitope as trastuzumab but the Fc part of the antibody is optimized for a better antibody-dependent cellular cytotoxicity, ADCC, > Fig. 1 than trastuzumab [20]. Studies with trastuzumab had shown that a portion of the patients with a certain genotype in the Fc receptor which is present in a majority of 


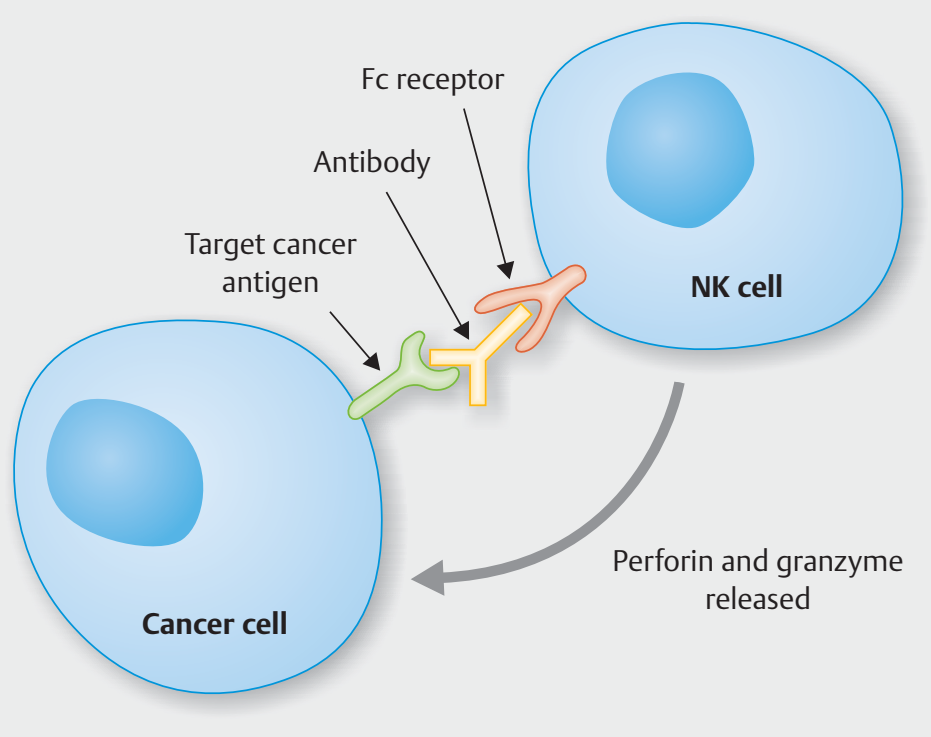

- Fig. 1 Antibody-dependent cellular mediated cytotoxicity (ACDD). The antibody binds to the target cell. The Fc part of the antibody binds with Fc receptors of natural killer cells which mediate the cytotoxicity.

patients responds more poorly to trastuzumab [21,22], since the Fc part of the antibody has a low affinity for the Fc receptors of the natural killer (NK) cells. Antibodies which can overcome these weaknesses may have better efficacy. The Sophia study investigated margetuximab in a large phase III study. 536 patients who were pretreated with trastuzumab and pertuzumab were randomised and received a combination of trastuzumab or margetuximab with chemotherapy (capecitabine, eribulin, navelbine or gemcitabine at the discretion of the physician) [20]. The therapy with margetuximab + chemotherapy demonstrated a significantly better median PFS (5.8 vs. 4.9 months, $\mathrm{HR}=0.76$; $95 \% \mathrm{Cl}$ : $0.59-$ $0.98 p=0.033$ ). The efficacy was higher in the group of patients with the low affinity allele of the Fc receptor. The overall response was also higher in the margetuximab group (22 vs. 16\%). The adverse effect profile in both groups was comparable. The new substances neratinib, pyrotinib and margetuximab appear promising, however they are not yet approved in Germany. Further studies to confirm the results are necessary.

\section{Metastatic TNBC}

\section{Patients with TNBC are predisposed for immunotherapy}

The discovery of the "immunological synapse", the so-called checkpoint in the immune system with activating and inhibiting receptors which can be stimulated or curbed via the T-cell activity [23] was awarded the Nobel Prize in medicine in autumn 2018 [24]. The development of monoclonal antibodies which block inhibiting receptors so as to override their inhibitory function and so that an activation of immunocompetent $\mathrm{T}$ cells can ultimately take place was pioneering for a new cornerstone of medical tumour therapy which has been established since 2011 in a number of tumour entities. These antibodies, known as checkpoint inhibitors, block various inhibiting receptors which are known as CTLA4, PD-1 and PD-L1 [25].

Almost at the same time as the awarding of the Nobel Prize in medicine, it was known that this mode of action also has potential in locally advanced or metastatic triple-negative breast cancer (mTNBC) [26, 27].

The second interim analysis of the phase III study IMpassion130, which was presented at the ASCO 2019 [27], highlights the importance of this new therapy option for patients with metastatic TNBC: Patients with a PD-L1 expression on tumour-infiltrating immune cells (IC) in > $1 \%$ of the immune cells survived a median of 7 months longer when they received a combination of the PD-L1 inhibitor atezolizumab and the cytostatic agent nab-paclitaxel, in comparison to a combination of placebo and nab-paclitaxel (25.0 vs. 18.0 months). The mortality risk decreased in this patient group by $29 \%$ (HR: $0.71 ; 95 \% \mathrm{Cl}: 0.54-0.93)$. More than half of PD-L1 IC-positive patients treated with atezolizumab were still alive after 2 years ( 51 vs. $37.5 \%$ in the comparison arm).

The risk of progression also significantly decreased by $38 \%$ (median PFS: 7.46 vs. 4.96 months placebo/nab-paclitaxel; $\mathrm{HR}=0.62 ; 95 \% \mathrm{Cl}: 0.49-0.78 ; \mathrm{p}<0.0001)$. The combination therapy proved to be safe and well tolerated.

Since the combination of atezolizumab and chemotherapy alone in the case of PD-L1 expression on IC which make up more than $1 \%$ of the surface of the tumour proved to be effective, the testing is of key importance [28]. Similar to the HER2 testing, the PD-L1 IC testing must become established as a new standard. The use of validated tests is obligatory.

The adverse events were consistent with the known safety profiles of the monopreparations. However, a challenge is the adverse effect profile of the checkpoint inhibitors which significantly differs from that of chemotherapy: As a consequence of the acti- 


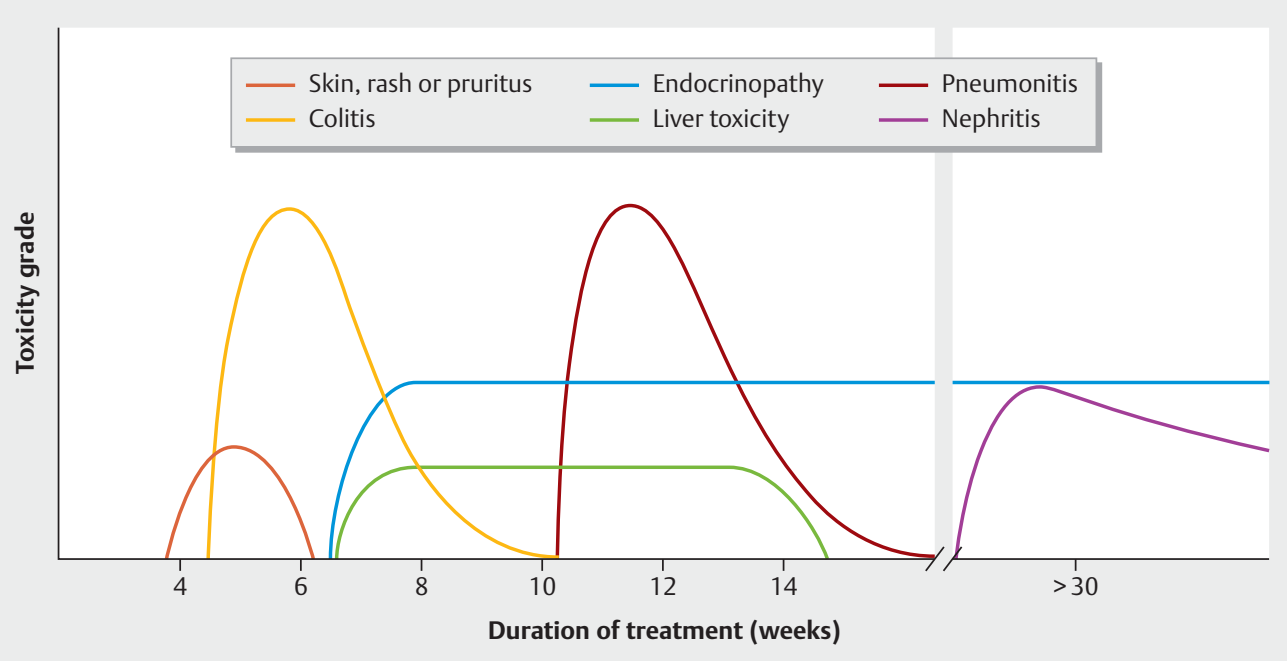

- Fig. 2 Overview of the main immunotherapy-related adverse effects (irAEs) in patients who received anti-PD1 or anti-PDL1-based therapy (reprinted with permission from NatureSpringer from [62], https://www.nature.com/articles/s41571-019-0218-0).

vation of immunocompetent T cells, there may be immune-mediated adverse effects (immune related adverse events, irAE). According to the available data from the IMpassion-130 study, these are indeed rare and are only rarely severe, but the time at which they occur differs significantly from the adverse effects caused by chemotherapy. The appearance of irAE months after the start of therapy must be expected, in principle. Thus there may be, for example, immune-mediated pneumonitis, colitis or dermatitis. The prompt detection of irAE is crucial and in general, they can be successfully treated with steroids. A typical chronological sequence is shown in $\mathbf{r i g} \mathbf{~} \mathbf{2}$.

Because of the high need for new therapeutic options in metastatic TNBC, the current data from the IMpassion-130 study are of particular relevance.

Based on the data, the Association of Gynaecological Oncology (AGO) assesses the first-line use of atezolizumab with nab-paclitaxel in patients with positive PD-L1 status for IC with a "plus" even before approval. Atezolizumab in combination with nab-paclitaxel for mTNBC was approved by the FDA on 11 March 2019 in the US. EU approval is expected in autumn 2019.

\section{Opportunities for the treatment of TNBC are in the tumour biology}

Patients with TNBC have not only an extremely poor prognosis but the tumours in particular lack points of attack which can be used for therapy. In the case of a BRCA1/2 germ line mutation, however, other aspects of the biology of this type of tumour are known. Because of this, initial therapies which are based on these points of attack are already available. These are the PARP inhibitors which can also be used in the case of hormone-receptor-positive, HER2negative patients. In the two studies OlympiaD and EMBRACA, the efficacy in metastatic, BRCA1/2-germ-line-mutating breast cancer was established (TNBC and HR+ HER-). [29, 30]. The final overall survival data for olaparib were presented in a recently published work. In the overall population, no significant advantage with regard to overall survival was reported (HR 0.51 [95\% Cl $0.29,0.90]$; $p=0.02$ ). However, in a subgroup analysis, an advantage for overall survival in favour of the olaparib arm was seen for patients who had not yet received any prior chemotherapy in an advanced therapy situation (HR 0.51 [95\% Cl $0.29,0.90]$; $p=0.02$ ). The corresponding Kaplan-Meier curve is shown in - Fig. 3. In the case of therapy with olaparib, a median OS of 22.4 months was reached in this subgroup, while in the case of patients who were treated only with chemotherapy, a median OS of 14.7 months was noted [31].

A precondition for therapy with a PARP inhibitor is the detection of a germ line mutation in BRCA1 or BRCA2. In the metastatic situation, some studies have been conducted on the frequency of these mutations. While in the case of patients with TNBC, a mutation was able to be found in $9.5 \%$ of the patients with advanced breast cancer, a BRCA1/2 mutation was present in $4.4 \%$ in luminal A like and luminal B like tumours and in $4.7 \%$ of the patients [32]. Testing for all patients in this group for whom therapy with a PARP inhibitor would be clinically indicated would thus make sense. A reflection on the therapy algorithms for these patients can be found in Schneeweiss et al. [33] where, in the first-line therapy in patients with $B R C A 1 / 2$ mutations, immunotherapy competes with PARP inhibitor therapy, because for both studies, a survival advantage in subgroups in the first line of therapy was demonstrated.

\section{Supportive Therapy}

\section{Supportive therapy as an integral component of oncological care}

Supportive therapy is an essential component of all cancer therapies and all oncological care concepts. This includes the treatment of adverse effects as well as the general improvement in healthrelated well-being. It includes, for example, the treatment of adverse effects such as musculoskeletal symptoms and osteopenia 


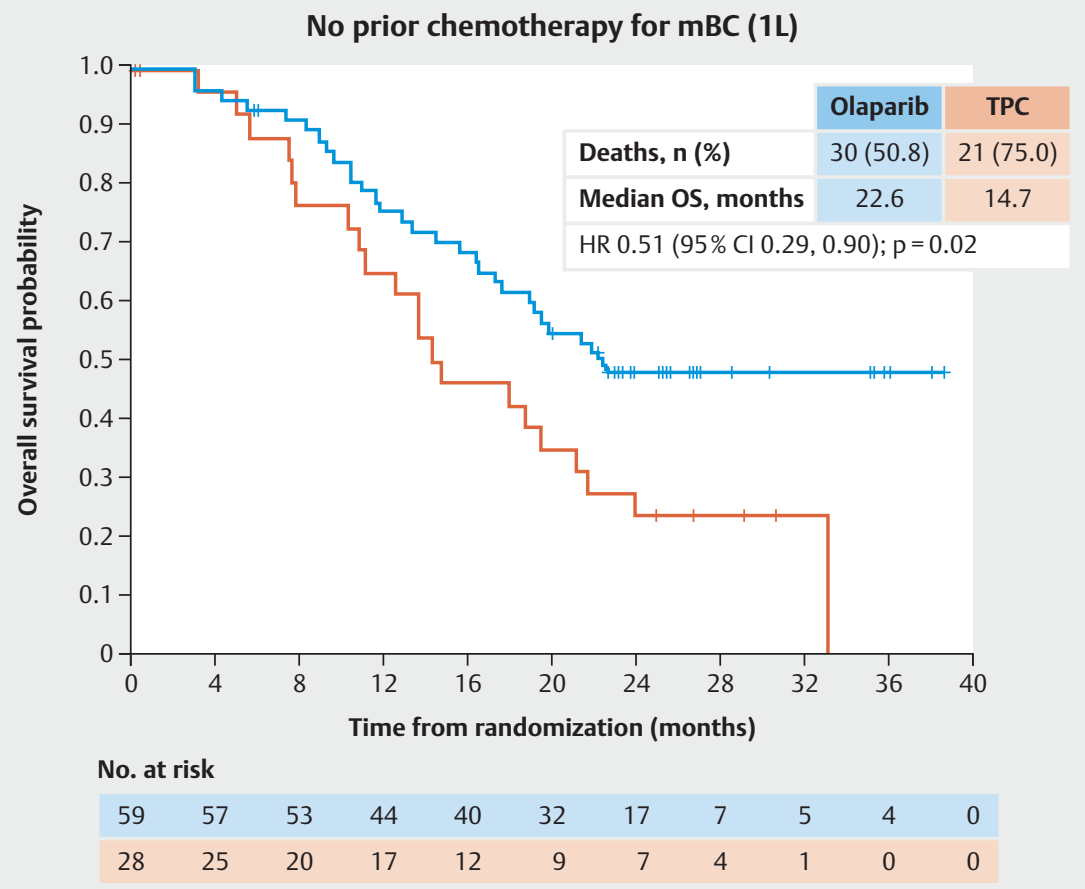

- Fig. 3 Kaplan Meier estimators for the overall survival for patients in the OlympiaD study without previous chemotherapy in the metastatic situation (TPC: Treatment of physician's choice).

in the case of antihormonal therapy, the treatment of stomatitis in mTOR inhibition, the treatment of leukopaenia in CDK4/6 inhibitor therapy or myelosuppression in chemotherapy. However, information for patients and family members and psycho-oncological support and counselling are also a component of supportive therapy [34-36]. The most important objective is the improvement in quality of life and the avoidance of long-term damage. However, a good rationale as to why good supportive therapy can improve the efficacy of therapies can also be found. Thus it is known, for example, that patients on adjuvant and metastatic therapy with aromatase inhibitors discontinue a considerable portion of them without progression $[8,37]$. This is frequently the case in particular when patients experience new adverse effects at the start of therapy $[8,38]$. In the adjuvant situation, it has already been proven that poor compliance also correlates with a worse outcome [39]. In view of this, adverse effects, quality of life and its supportive therapy should in particular be taken seriously. New study data are rather rare and often do not gain any significant attention.

\section{New data on zoledronic acid therapy}

The S0702 study of the SWOG (Southwest Cancer Chemotherapy Study Group) was to determine the frequency of osteonecrosis of the jaw (ONJ) after 3 years of zolendronic acid therapy as a primary study objective. In addition, risk factors for ONJ were to be determined. A total of 3491 patients with bone metastases from various primary tumour entities (breast: $32 \%$, prostate: $20 \%$, lung: $19 \%$, multiple myeloma: $17 \%$, other: $12 \%$ ) who were receiving therapy with zolendronic acid were included. After 3 years, the cumulative incidence of ONJ was $2.8 \%$. Patients whose dosing interval was 3-4 weeks had a risk nearly five times as high of developing $\mathrm{ONJ}$ as compared to patients with a prolonged dosing interval (HR 4.80, 95\% Cl 1.52-15.18, $\mathrm{p}=0.008$ ). Additional risk factors for zolendronate-associated ONJ were identified as pre-existing dental disease and existing nicotine abuse [40].

In view of the fact that there is by now sufficient evidence that the zolendronate therapy is also effective with a prolonged dosing interval [41], these data should be considered to be clinically quite relevant. They support the current therapeutic recommendation of the AGO, which gave zolendronate in the 12-week dosing the highest level of recommendation of “++" [42,43]. By implementing this recommendation, the risk of the occurrence of the adverse effect of ONJ, which is rather rare overall but represents significant impairment for the patient, on zoledronate therapy can be reduced. 
Access to the Healthcare System and Medical Care

\section{Medical care as a political topic}

The discussion of the best medical care given limited resources has been a part of public and political discussion in Germany for a long time. In the case of new therapies, the benefit assessment process repeatedly leads to a discussion between professional associations, the Federal Joint Committee (G-BA) and the pharmaceutical industry on what actually constitutes a benefit of drugs.

Patients' insurance status is also a point of discussion about which not many investigations on endpoint research are found in the literature. Investigations on, for example, waiting times for an appointment or other indicators of medical care organisation were found $[44,45]$ which demonstrate that, for example, private patients in Germany have shorter waits for a medical appointment. Theoretically this could also be a disadvantage for patients in the case of diseases which lead to a worse treatment result in the event of a longer "lead time". However, the investigations also demonstrated that even in the case of statutory health insurance patients, the waiting time, on an international comparison, is extremely low [45]. In the case of the digitalisation in healthcare as required by the German federal government, it is foreseeable that data on issues relating to healthcare and the factors which influence its quality can be expected soon [46].

\section{The US - The Affordable Care Act}

In other countries as well, such as the US, such connections are discussed and researched. The Affordable Care Act in the US, initiated by Barack Obama, had the objective of enabling more people to have access to appropriate medical care and also simultaneously rectifying racial differences [47]. The assumption of costs through Medicaid was to be promptly adapted in the individual states, however not all states in the US actually implemented this. As a result, there was an inconsistent picture: states with a Medicaid adaptation and those without an adjustment. The time period from initial diagnosis until initiation of systemic therapy can be used as a possible measurement for appropriate oncological care. In a data-based, retrospective investigation it was asked whether the non-initiation of Medicaid led to a statistically significant delayed access to oncological care, particularly in the case of black US citizens as compared to white US citizens. Records from 30386 cancer patients (NSCLC, breast carcinoma, urothelial carcinoma, colorectal carcinoma, renal cell carcinoma, prostate carcinoma, melanoma, stomach and oesophageal carcinoma) from 2011 to 2019 were used for this purpose. Patients who died within 30 days after diagnosis were not taken into consideration. It was noted that in states with expanded Medicaid, in comparison to states without an expansion, $6.1 \%$ more African-American citizens had access to adequate care; among Caucasian citizens, the difference was only $2 \%$ [47]. In addition to the political appeal and criticism, these data are above all a plea for the creation of large databases with the objective of knowledge-generating care, independent of the structure of a healthcare system. Greater advancements can be expected here in the near future with the increasing digitalisation of medicine [48 - 52].

\section{Outlook}

The approval of alpelisib is expected in the course of this year. Thus, in addition to therapy with atezolizumab (PD-L1 positivity on immune cells required in the tumour) and olaparib (germ line BRCA $1 / 2$ mutation required), a third drug will be available which is associated with companion diagnostics. In the case of PIK3CA testing, it will be discussed whether testing from the tumour or blood will be the best for patients and the most effective for the healthcare system; in the case of the anti-PD1/PDL1 therapies, a multitude of antibodies and various tests are available and associated with various drugs and indications. Establishing these companion diagnostics in a quality-assured manner is certainly an interdisciplinary challenge which must be overcome. For the patients and also the therapists, this identification of patient groups is precisely the goal which has been worked towards for many years. It should be considered a great success that this form of therapy has now found its way into the treatment of patients with breast cancer.

\section{Acknowledgements}

This work was developed in part as a result of support from Hexal and the PRAEGNANT network which is supported by Pfizer, Celgene, Daiichi Sankyo, Roche, Merrimack, Eisai, AstraZeneca, Hexal and Novartis. None of the companies played a role in the drafting of this manuscript. The authors alone are responsible for the content of the manuscript.

\section{Conflict of Interest}

A.D.H. received speaker and consultancy honoraria from AstraZeneca, Genomic Health, Roche, Novartis, Celgene, Lilly, MSD, Eisai, Teva, Tesaro, Daiichi Sankyo, Hexal and Pfizer. F. O. received speaker and consultancy honoraria from Amgen, AstraZeneca, Bayer, BMS, BoehringerIngelheim, Chugai, Celgene, Cellex, Eisai, Gilead, Hexal, Ipsen, JanssenCilag, Merck, MSD, Novartis, Riemser, Roche, Tesaro, Teva. H.-C. K. received honoraria from Carl Zeiss meditec, Teva, Theraclion, Novartis, Amgen, AstraZeneca, Pfizer, Janssen-Cilag, GSK, LIV Pharma, Roche and Genomic Health. P. A. F. received honoraria from Novartis, Pfizer, Roche, Amgen, Celgene, Daiichi Sankyo, AstraZeneca, MSD, Eisai, Puma and Teva. His institution conducts research with funding from Novartis and Biontech. M. W. received speakers honoraria and consultant fees from Novartis, Amgen, Celgene, Roche, Genentech, AstraZeneca, and Pfizer. H. T. received honoraria from Novartis, Roche, Celgene, Teva, Pfizer and travel support from Roche, Celgene and Pfizer. J. E. received honoraria from AstraZeneca, Roche, Celgene, Novartis, Lilly, Pfizer, Pierre Fabre, Teva and travel support from Celgene, Pfizer, Teva and Pierre Fabre. M.P.L. has participated on advisory boards for AstraZeneca, MSD, Novartis, Pfizer, Eisai, Genomic Health and Roche and has received honoraria for lectures from MSD, Lilly, Roche, Novartis, Pfizer, Genomic Health, AstraZeneca, medac and Eisai. V. M. received speaker honoraria from Amgen, AstraZeneca, Celgene, Daiichi Sankyo, Eisai, Pfizer, Novartis, Roche, Teva, Janssen-Cilag and consultancy honoraria from Genomic Health, Hexal, Roche, Pierre Fabre, Amgen, Novartis, MSD, Daiichi Sankyo and Eisai, Lilly, Tesaro and Nektar. E. B. received honoraria from Novartis, Hexal, Amgen, and onkowissen.de for consulting, clinical research management or medical education activities. A.S. received honoraria from Roche, Celgene, AstraZeneca, Novartis, Pfizer, Zuckschwerdt Verlag GmbH, Georg Thieme Verlag, Aurikamed GmbH, MCl Deutschland $\mathrm{GmbH}$, bsh medical communications $\mathrm{GmbH}$ and promedicis $\mathrm{GmbH}$. W. J. received honoraria and research grants from Novartis, Roche, Pfizer, Lilly, AstraZeneca, Chugai, Sanofi, Daiichi Sankyo, Tesaro. F. S. participated on advisory boards for Novartis, Lilly, Amgen and Roche and received honoraria for lectures from Roche, AstraZeneca, MSD, 
Novartis and Pfizer. A. W. participated on advisory boards for Novartis, Lilly, Amgen, Pfizer, Roche, Tesaro, Eisai and received honoraria for lectures from Novartis, Pfizer, Aurikamed, Roche, Celgene. D. L. received honorarium from Amgen, AstraZeneca, Celgene, Lilly, Loreal, MSD, Novartis, Pfizer, Tesaro, Teva. T. N. F. has participated on advisory boards for Amgen, Daiichi Sankyo, Novartis, Pfizer, and Roche and has received honoraria for lectures from Amgen, Celgene, Daiichi Sankyo, Roche, Novartis and Pfizer.

\section{References}

[1] Lux MP, Fasching PA, Schrauder MG et al. The PI3K Pathway: Background and Treatment Approaches. Breast Care (Basel) 2016; 11: 398-404

[2] Jones RH, Carucci M, Casbard AC et al. Capivasertib (AZD5363) plus fulvestrant versus placebo plus fulvestrant after relapse or progression on an aromatase inhibitor in metastatic ER-positive breast cancer (FAKTION): A randomized, double-blind, placebo-controlled, phase II trial. J Clin Oncol 2019; 37: Abstr. 1005

[3] Im SA, Lu YS, Bardia A et al. Overall Survival with Ribociclib plus Endocrine Therapy in Breast Cancer. N Engl J Med 2019. doi:10.1056/ NEJMoa 1903765

[4] Novartis. Novartis Kisqali significantly prolongs life in women with HR +/HER2- advanced breast cancer now in two distinct Phase III trials. 2019. Online: https://www.novartis.com/news/media-releases/ novartis-kisqali-significantly-prolongs-life-women-hrher2-advancedbreast-cancer-now-two-distinct-phase-iii-trials; last access: 03.08.2019

[5] Slamon DJ, Neven P, Chia S et al. Phase III Randomized Study of Ribociclib and Fulvestrant in Hormone Receptor-Positive, Human Epidermal Growth Factor Receptor 2-Negative Advanced Breast Cancer: MONALEESA-3. J Clin Oncol 2018; 36: 2465-2472. doi:10.1200/ JCO.2018.78.9909

[6] Park YH, Kim TY, Kim GM et al. A randomized phase II study of palbociclib plus exemestane with GNRH agonist versus capecitabine in premenopausal women with hormone receptor-positive metastatic breast cancer (KCSG-BR 15-10, NCT02592746). J Clin Oncol 2019. doi:10.1200/ JCO.2019.37.15_suppl.1007

[7] Hartkopf AD, Huober J, Volz B et al. Treatment landscape of advanced breast cancer patients with hormone receptor positive HER2 negative tumors - Data from the German PRAEGNANT breast cancer registry. Breast 2018; 37: 42-51

[8] Wallwiener M, Nabieva N, Feisst M et al. Influence of patient and tumor characteristics on therapy persistence with letrozole in postmenopausal women with advanced breast cancer: results of the prospective observational EvAluate-TM study. BMC Cancer 2019; 19: 611

[9] Tolaney SM, Barroso-Sousa R, Keenan T et al. Randomized phase II study of eribulin mesylate $(E)$ with or without pembrolizumab $(P)$ for hormone receptor-positive $\left(\mathrm{HR}^{+}\right)$metastatic breast cancer (MBC). J Clin Oncol 2019. doi:10.1200/JCO.2019.37.15_suppl.1004

[10] Andre F, Ciruelos E, Rubovszky G et al. Alpelisib for PIK3CA-Mutated, Hormone Receptor-Positive Advanced Breast Cancer. N Engl J Med 2019; 380: 1929-1940

[11] Swain SM, Baselga J, Kim SB et al. Pertuzumab, trastuzumab, and docetaxel in HER2-positive metastatic breast cancer. N Engl J Med 2015; 372: 724-734

[12] Baselga J, Cortes J, Kim SB et al. Pertuzumab plus trastuzumab plus docetaxel for metastatic breast cancer. N Engl J Med 2012; 366: 109-119

[13] Swain SM, Miles D, Kim SB et al. End-of-study analysis from the phase III, randomized, double-blind, placebo (Pla)-controlled CLEOPATRA study of first-line $(1 \mathrm{~L})$ pertuzumab $(\mathrm{P})$, trastuzumab $(\mathrm{H})$, and docetaxel $(\mathrm{D})$ in patients (pts) with HER2-positive metastatic breast cancer (MBC). J Clin Oncol 2019. doi:10.1200/JCO.2019.37.15_suppl.1020
[14] Lux MP, Nabieva N, Hartkopf AD et al. Therapy Landscape in Patients with Metastatic HER2-Positive Breast Cancer: Data from the PRAEGNANT Real-World Breast Cancer Registry. Cancers (Basel) 2018. doi:10.3390/ cancers 11010010

[15] Saura C, Oliveira M, Feng YH et al. Neratinib + capecitabine versus lapatinib + capecitabine in patients with HER2+ metastatic breast cancer previously treated with $\geq 2$ HER2-directed regimens: Findings from the multinational, randomized, phase III NALA trial. J Clin Oncol 2019. doi:10.1200/JCO.2019.37.15_suppl.1002

[16] Powell CA, Camidge DR, Gemma A et al. Characterization, monitoring, and management of interstitial lung disease in patients with metastatic breast cancer: Analysis of data available from multiple studies of DS8201a, a HER2-targeted antibody drug conjugate with a topoisomerase I inhibitor payload. San Antonio Breast Cancer Symposium 2018; Abstr. P6-17-06

[17] Modi S, Tsurutani J, Takahashi S et al. Safety and efficacy results from a phase 1 study of DS-8201a in patients with HER2 expressing breast cancers. Cancer Res 2018. doi:10.1158/1538-7445.SABCS17-PD3-07

[18] Iwata H, Tamura K, Doi T et al. Trastuzumab deruxtecan (DS-8201a) in subjects with HER2-expressing solid tumors: Long-term results of a large phase 1 study with multiple expansion cohorts. J Clin Oncol 2018; 36 (Suppl.): Abstr. 2501

[19] Jiang Z, Yan M, Hu X et al. Pyrotinib combined with capecitabine in women with HER2+ metastatic breast cancer previously treated with trastuzumab and taxanes: A randomized phase III study. J Clin Oncol 2019. doi:10.1200/JCO.2019.37.15_suppl.1001

[20] Rugo HS, Im SA, Wright GLS et al. SOPHIA primary analysis: A phase 3 (P3) study of margetuximab (M) + chemotherapy (C) versus trastuzumab (T) + C in patients (pts) with HER2 + metastatic (met) breast cancer (MBC) after prior anti-HER2 therapies (Tx). J Clin Oncol 2019. doi:10.1200/JCO.2019.37.15_suppl.1000

[21] Musolino A, Naldi N, Bortesi B et al. Immunoglobulin G fragment C receptor polymorphisms and clinical efficacy of trastuzumab-based therapy in patients with HER-2/neu-positive metastatic breast cancer. J Clin Oncol 2008; 26: 1789-1796

[22] Gavin PG, Song N, Kim SR et al. Association of Polymorphisms in FCGR2A and FCGR3A With Degree of Trastuzumab Benefit in the Adjuvant Treatment of ERBB2/HER2-Positive Breast Cancer: Analysis of the NSABP B-31 Trial. JAMA Oncol 2017; 3: 335-341

[23] Chen DS, Mellman I. Oncology meets immunology: the cancer-immunity cycle. Immunity 2013; 39: 1-10

[24] Nobel Media. The Nobel Prize in Physiology or Medicine 2018. 2018. Online: https://www.nobelprize.org/prizes/medicine/2018/summary/; last access: 11.10.2018

[25] Emens LA, Kok M, Ojalvo LS. Targeting the programmed cell death-1 pathway in breast and ovarian cancer. Curr Opin Obstet Gynecol 2016; 28: $142-147$

[26] Schmid P, Adams S, Rugo HS et al. Atezolizumab and Nab-Paclitaxel in Advanced Triple-Negative Breast Cancer. N Engl J Med 2018; 379: 2108-2121

[27] Schmid P, Adams S, Rugo HS et al. IMpassion130: updated overall survival (OS) from a global, randomized, double-blind, placebo-controlled, Phase III study of atezolizumab (atezo) + nab-paclitaxel (nP) in previously untreated locally advanced or metastatic triple-negative breast cancer (mTNBC). J Clin Oncol 2019. doi:10.1200/ JCO.2019.37.15_suppl.1003

[28] Emens LA, Loi S, Rugo HS et al. IMpassion130: Efficacy in immune biomarker subgroups from the global, randomized, double-blind, placebocontrolled, phase III study of atezolizumab + nab-paclitaxel in patients with treatment-nave, locally advanced or metastatic triple-negative breast cancer. San Antonio Breast Cancer Symposium 2018; Abstr. GS104 
[29] Robson M, Im S-A, Senkus E et al. Olaparib for Metastatic Breast Cancer in Patients with a Germline BRCA Mutation. N Engl J Med 2017; 377: 523-533

[30] Litton J, Rugo HS, Ettl J et al. EMBRACA: A phase 3 trial comparing talazoparib, an oral PARP inhibitor, to physician's choice of therapy in patients with advanced breast cancer and a germline BRCA mutation [abstract]. In: Proceedings of the 2017 San Antonio Breast Cancer Symposium; 2017 Dec 5-9; San Antonio, TX Philadelphia (PA): AACR. Cancer Res 2018; 78: Abstr. GS6-07

[31] Robson ME, Tung N, Conte $P$ et al. OlympiAD final overall survival and tolerability results: Olaparib versus chemotherapy treatment of physician's choice in patients with a germline BRCA mutation and HER2-negative metastatic breast cancer. Ann Oncol 2019; 30: 558-566

[32] Fasching P, Hu C, Hart S et al. Abstract PD1-02: Cancer predisposition genes in metastatic breast cancer - Association with metastatic pattern, prognosis, patient and tumor characteristics. Cancer Res 2018; 78: PD102-PD01-02

[33] Schneeweiss A, Denkert C, Fasching PA et al. Diagnosis and Therapy of Triple-Negative Breast Cancer (TNBC) - Recommendations for Daily Routine Practice. Geburtsh Frauenheilk 2019; 79: 605-617

[34] Cardoso F, Bese N, Distelhorst SR et al. Supportive care during treatment for breast cancer: resource allocations in low- and middle-income countries. A Breast Health Global Initiative 2013 consensus statement. Breast 2013; 22: 593-605

[35] Ganz PA, Yip CH, Gralow JR et al. Supportive care after curative treatment for breast cancer (survivorship care): resource allocations in lowand middle-income countries. A Breast Health Global Initiative 2013 consensus statement. Breast 2013; 22: 606-615

[36] Harrison JD, Young JM, Price MA et al. What are the unmet supportive care needs of people with cancer? A systematic review. Support Care Cancer 2009; 17: 1117-1128

[37] Nabieva N, Kellner S, Fehm T et al. Influence of patient and tumor characteristics on early therapy persistence with letrozole in postmenopausal women with early breast cancer: results of the prospective Evaluate-TM study with 3941 patients. Ann Oncol 2018; 29: 186-192

[38] Nabieva N, Fehm T, Haberle L et al. Influence of side-effects on early therapy persistence with letrozole in post-menopausal patients with early breast cancer: Results of the prospective EvAluate-TM study. Eur J Cancer 2018; 96: 82-90

[39] Chirgwin JH, Giobbie-Hurder A, Coates AS et al. Treatment Adherence and Its Impact on Disease-Free Survival in the Breast International Group 1-98 Trial of Tamoxifen and Letrozole, Alone and in Sequence. J Clin Oncol 2016; 34: 2452-2459

[40] Van Poznak CH, Unger JM, Darke AK et al. Osteonecrosis of the jaw in patients with cancer receiving zoledronic acid for bone metastases: SWOG S0702, NCT00874211. J Clin Oncol 2019; 37 (Suppl.): Abstr. 11502

[41] Himelstein AL, Foster JC, Khatcheressian JL et al. Effect of Longer-Interval vs. Standard Dosing of Zoledronic Acid on Skeletal Events in Patients With Bone Metastases: A Randomized Clinical Trial. JAMA 2017; 317: 48-58

[42] Thill M, Liedtke C, Muller V et al. AGO Recommendations for the Diagnosis and Treatment of Patients with Advanced and Metastatic Breast Cancer: Update 2018. Breast Care (Basel) 2018; 13: 209-215

[43] Liedtke C, Jackisch C, Thill M et al. AGO Recommendations for the Diagnosis and Treatment of Patients with Early Breast Cancer: Update 2018. Breast Care (Basel) 2018; 13: 196-208

[44] Klein-Schmeink M. Warten Kassenpatienten in NRW länger auf einen Facharzttermin als privat Versicherte? 2017. Online: https://www.kleinschmeink.de/data/user/PDF-Dokumente/2017/Wartezeiten_NRW_ 2017.pdf; last access: 24.07.2017

[45] Kopetsch T; Kassenärztliche Bundesvereinigung. Wartezeiten in der ambulanten Versorgung. 2014. Online: http://www.kbv.de/media/sp/ wartezeiten_studie_kopetsch.pdf; last access: 24.07.2019
[46] Bundesministerium für Gesundheit. E-Health - Digitalisierung im Gesundheitswesen. 2018. Online: https://www.bundesgesundheitsministerium.de/e-health-initiative.html; last access: 24.07.2019

[47] Adamson BJS, Cohen AB, Estevez $M$ et al. Affordable Care Act (ACA) Medicaid expansion impact on racial disparities in time to cancer treatment. J Clin Oncol 2019. doi:10.1200/JCO.2019.37.18_suppl.LBA1

[48] Fasching PA, Hartkopf AD, Gass P et al. Efficacy of neoadjuvant pertuzumab in addition to chemotherapy and trastuzumab in routine clinical treatment of patients with primary breast cancer: a multicentric analysis. Breast Cancer Res Treat 2019; 173: 319-328

[49] Hartkopf AD, Graf J, Simoes E et al. Electronic-Based Patient-Reported Outcomes: Willingness, Needs, and Barriers in Adjuvant and Metastatic Breast Cancer Patients. JMIR Cancer 2017; 3: e11

[50] Tresp V, Overhage JM, Bundschus M et al. Going Digital: A Survey on Digitalization and Large-Scale Data Analytics in Healthcare. P IEEE 2016; 104: 2180-2206

[51] Wallwiener M, Heindl F, Brucker SY et al. Implementation and Feasibility of Electronic Patient-Reported Outcome (ePRO) Data Entry in the PRAEGNANT Real-Time Advanced and Metastatic Breast Cancer Registry. Geburtsh Frauenheilk 2017; 77: 870-878

[52] Wallwiener M, Matthies L, Simoes E et al. Reliability of an e-PRO Tool of EORTC QLQ-C30 for Measurement of Health-Related Quality of Life in Patients With Breast Cancer: Prospective Randomized Trial. J Med Internet Res 2017; 19: e322

[53] Finn RS, Crown JP, Lang I et al. The cyclin-dependent kinase 4/6 inhibitor palbociclib in combination with letrozole versus letrozole alone as firstline treatment of oestrogen receptor-positive, HER2-negative, advanced breast cancer (PALOMA-1/TRIO-18): a randomised phase 2 study. Lancet Oncol 2015; 16: 25-35

[54] Finn RS, Martin M, Rugo HS et al. Palbociclib and Letrozole in Advanced Breast Cancer. N Engl J Med 2016; 375: 1925-1936

[55] Verma S, Bartlett $\mathrm{CH}$, Schnell P et al. Palbociclib in Combination With Fulvestrant in Women With Hormone Receptor-Positive/HER2-Negative Advanced Metastatic Breast Cancer: Detailed Safety Analysis From a Multicenter, Randomized, Placebo-Controlled, Phase III Study (PALOMA-3). Oncologist 2016; 21: 1165-1175

[56] Cristofanilli M, Turner NC, Bondarenko I et al. Fulvestrant plus palbociclib versus fulvestrant plus placebo for treatment of hormone-receptor-positive, HER2-negative metastatic breast cancer that progressed on previous endocrine therapy (PALOMA-3): final analysis of the multicentre, double-blind, phase 3 randomised controlled trial. Lancet Oncol 2016; 17: 425-439

[57] Hortobagyi GN, Stemmer SM, Burris HA et al. Ribociclib as First-Line Therapy for HR-Positive, Advanced Breast Cancer. N Engl J Med 2016; 375: $1738-1748$

[58] Hortobagyi GN, Stemmer SM, Burris HA et al. Updated results from MONALEESA-2, a phase III trial of first-line ribociclib plus letrozole versus placebo plus letrozole in hormone receptor-positive, HER2-negative advanced breast cancer. Ann Oncol 2018; 29: 1541-1547

[59] Tripathy D, Im SA, Colleoni M et al. Ribociclib plus endocrine therapy for premenopausal women with hormone-receptor-positive, advanced breast cancer (MONALEESA-7): a randomised phase 3 trial. Lancet Oncol 2018. doi:10.1016/S1470-2045(18)30292-4

[60] Sledge GW jr., Toi M, Neven P et al. MONARCH 2: Abemaciclib in Combination With Fulvestrant in Women With HR+/HER2- Advanced Breast Cancer Who Had Progressed While Receiving Endocrine Therapy. J Clin Oncol 2017; 35: 2875-2884

[61] Goetz MP, Toi M, Campone M et al. MONARCH 3: Abemaciclib As Initial Therapy for Advanced Breast Cancer. J Clin Oncol 2017; 35: 3638-3646

[62] Martins F, Sofiya L, Sykiotis GP et al. Adverse effects of immune-checkpoint inhibitors: epidemiology, management and surveillance. Nat Rev Clin Oncol 2019. doi:10.1038/s41571-019-0218-0 